\title{
Analisis Pemlastis DOP dalam Resin $P V C$ terhadap Kekuatan Tarik Alas Sandal Simetri
}

\author{
Yogi Dhani Ermaniardo ${ }^{1}$ dan Syamsul Hadi ${ }^{2}$ \\ 1,2 Teknik Mesin, Politeknik Negeri Malang, Jalan Soekarno Hatta No.9, Malang, 65141, Indonesia \\ 1 yogidanerdo@gmail.com \\ 2 syampol2003@yahoo.com
}

\begin{abstract}
If one side of sandals is broken, the other side cannot be used. From this problem have been made symmetry sandal which both sides are same. Then added the horizontal holes in the sandal to drain the water. The purpose of research is to mold the base of symmetry sandal and analyze the tensile strength materials. The materials are PVC resin (polyvinyl chloride, blowing agent, and black pigmen mixed with the DOP (diocthyl phthalate) or plasticizer variation and blowing agent. DOP variation used $300 \mathrm{ml}, 400 \mathrm{ml}$, and $500 \mathrm{ml}$ in $2000 \mathrm{~g}$ of PVC resin, $20 \mathrm{~g}$ blowing agent, and $20 \mathrm{~g}$ black pigmen. The material test is use tensile test for material. The research result is there is an effect of variations DOP In PVC resin on tensile strength, that tensile strength is decrease $46 \%$ from $16.20 \mathrm{MPa}$ to $8.74 \mathrm{MPa}$.
\end{abstract}

Keywords-component; symmetry base sandal, DOP, resin PVC, tensile strength

Abstrak-- Sandal jika satu sisinya rusak, maka sisi lainnya tidak dapat dipakai. Dari masalah tersebut telah dibuat sandal simetri yang kedua sisinya sama. Kemudian ditambahkan lubang pada alas sandal simetri untuk meniriskan air. Tujuan dari penelitian adalah untuk mencetak alas sandal simetri dan menganalisis kekuatan tarik bahan alas sandal simetri. Bahan yang digunakan yaitu resin $P V C$ (polyvinyl chloride) yang dicampur dengan variasi pemlastis DOP(diocthyl phthalate) dan bahan tambah blowing agent dan pigmen hitam. Variasi $D O P$ yang digunakan yaitu $300 \mathrm{ml}, 400 \mathrm{ml}$, dan $500 \mathrm{ml}$ dalam $2000 \mathrm{~g}$ resin $P V C, 20 \mathrm{~g}$ blowing agent, dan $20 \mathrm{~g}$ pigmen hitam. Pengujian yang dilakukan adalah pengujian tarik untuk bahan alas sandal. Hasil penelitian uji tarik adalah ada pengaruh variasi komposisi $D O P$ pada resin $P V C$ terhadap kekuatan tarik, yaitu menurunnya kekuatan tarik sebesar $46 \%$ dari 16,20MPa menjadi 8,74MPa.

Kata Kunci-Komponen; sandal simetri, DOP, resin PVC, kekuatan tarik

\section{Pendahuluan}

Penggunaan sandal japit terkadang jika salah satu sisi sandalnya rusak, maka sisi yang satunya tidak dapat dipakai. Untuk mengatasi masalah tersebut telah dibuat sandal simetri yang sisi kanan dan kirinya sama. Kemudian dikarenakan sandal japit banyak digunakan untuk keperluan yang berhubungan dengan tempat basah, maka ditambahkan lubang pada alas sandal simetri agar dapat meminimalisir air sisa pada alas kaki agar lebih tiris.

Agar dapat memperoleh produk yang diinginkan salah satu faktor yang dipertimbangkan adalah komposisi bahan yang tepat dan cetakan yang sesuai. Bahan sandal salah satunya adalah menggunakan resin polyvinyl chloride $(P V C)$ yang dicampur dengan bahan tambah yaitu pemlastis dioctylin phthalate $(D O P)$ dan bahan pengembang blowing agent.

Pada pembuatan sandal simetri sebelumnya telah dibuat sandal simetri yang terlalu lentur denga bahan silicon rubber sebagaimana Gambar 1. Bahan silicon rubber tersebut dalam pembuatannya tidak dilakukan pengujian bahan sebelum digunakan, sehingga tidak diketahui kekuatan bahan tersebut.

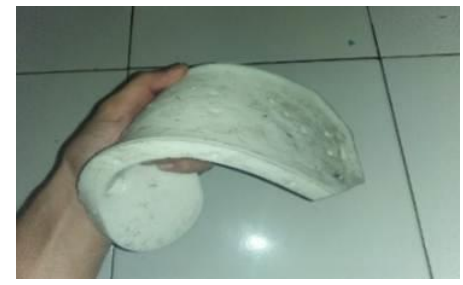

Gambar 1. Alas sandal simetri bahan silicon rubber

Tujuan peneilitan untuk mencari bahan alas sandal simetri yang tepat dan cukup elastis yang memungkinkan air teralirkan keluar melalui tepi sandal. Bahan sandal yang banyak digunakan adalah resin $P V C$. Bahan reisn $P V C$ yang dijadikan sandal dalam prosesnya dicampur dengan bahan tambah. 
Bahan tambah tersebut diantaranya pemlastis DOP, pengembang blowing agent, dan pewarna Pigmen hitam.

Umam (2009) telah meneliti mengenai pengaruh $D O P$ dalam resin $P V C$ terhadap melt flow ratenya. Tujuan penelitiannya adalah untuk mengetahui nilai melt flow rate variasi $D O P$ dalam resin $P V C$. Hasil dari penelitiannya adalah variasi $D O P$ mempengaruhi melt flow rate resn $P V C$ [1].

Penelitian selanjutnya dilakukan oleh Michael (2012) mengenai pengganti pemlastis DOP dengan pemlastis $D E D B$ (Diethylene Glycol Dibenzoate) pada resin $P V C$ terhadap modulus elastisitasnya. Hasil dari penelitiannya adalah pemlastis jenis $D E D B$ dapat menggantikan DOP pada resin $P V C$ [2].

Kemudian Sholeh (2018) meneliti juga mengenai pengaruh $D O P$ pada bahan kulit sintetis dari resin $P V C$. Tujuan penelitiannya adalah untuk mendapatkan kadar optimum DOP. Hasil dari peneiliannya adalah semakin banyak DOP maka kekuatan tarik kulit sintetis cenderung naik dan yang paling optimum pada 55phr DOP [3].

Dari penelitian sebelumnya dapat disimpulkan bahwa komposisi $D O P$ berpengaruh dalam resin $P V C$, maka dalam penelitian alas sandal yang menggunakan $D O P$ dan resin $P V C$ perlu dilakukan pengujian bahan untuk mengetahui kekuatan bahan sebelum digunakan dalam alas sandal. Salah satu pengujian yang dilakukan untuk mengetahui kekuatan bahan tersebut adalah pengujian tarik untuk mengetahui kekuatan tarik bahan tersebut.

Pengertian dari Kekuatan tarik adalah salah satu sifat dasar bahan. Hubungan antara tegangan dan regangan memberikan nilai yang cukup berubah, tergantung pada laju tegangannya [4].

Tegangan merupakan gaya per satuan luas dan diberi notasi $\sigma$. Dengan gaya disebut $F$ dan luas penampang disebut A, maka tegangan sebagaimana rumus (1) [5].

$$
\sigma=\frac{F}{A}
$$

dengan :
$\sigma:$ Tegangan
$\left(\mathrm{N} / \mathrm{mm}^{2}\right)$
F : Gaya
(N)
A : Luas Penampang $\left(\mathrm{mm}^{2}\right)$

Resin $P V C$ merupakan salah satu jenis polimer termoplastik. $P V C$ yang memiliki bentuk seperti tepung putih disebut resin $P V C$ dan resin $P V C$ memiliki masa jenis 1,4 . Temperatur yang cocok untuk pengolahan resin $P V C$ adalah $150^{\circ} \mathrm{C}$ sampai dengan $180{ }^{\circ} \mathrm{C}$ [4]. Salah satu cara pembentukan plastic termoplastik seperti $P V C$ yaitu dengan pencetak/ molding dan salah satu cetak injeksi adalah cetak injeksi/ injection molding. Cetak injeksi dapat digunakan untuk termoplastik atau karet [6]. Serbuk resin $P V C$ sebagaimana Gambar 2.

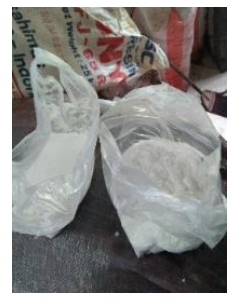

Gambar 2. Resin $P V C$

$D O P$ merupakan pemlastis yang sering digunakan. $D O P$ dikenal dengan sebutan general plasticizer yaitu pemlastis yang dapat digunakan untuk berbagai aplikasi. Penambahan DOP dapat meningkatkan fleksibiitas, kemampuan pembentukan, dan kemampuan proses PVC [1]. Cairan DOP sebagaimana Gambar 3.

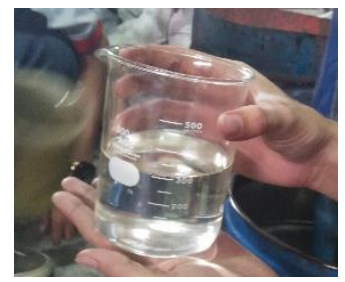

Gambar 3. Pemlastis DOP

\section{Metode Penelitian}

Penelitian dilakukan secara bertahap sebagaimana Gambar 4.

\section{A. Metode}

Variabel penelitian yang digunakan adalah variabel bebas, variabel tetap dan variabel terkontrol sebagai berikut:

1. Variabel bebas:

a) Variasi komposisi pemlastis $D O P 300 \mathrm{ml}$

b) Variasi komposisi pemlastis $D O P 400 \mathrm{ml}$

c) Variasi komposisi pemlastis DOP $500 \mathrm{ml}$

2. Variabel Terikat dalam penelitian ini adalah nilai gaya tarik.

3. Variabel Tetap:

a) Temperatur pengoprasian Injection Molding $180^{\circ} \mathrm{C}$. 
b) Komposisi resin PVC 2000g, Blowing Agent 20g, dan Pewarna hitam 20g.

\section{B. Gambar dan Tabel}

Proses pengerjaan penelitian dilakukan secara bertahap mulai dari persiapan, pencetakan, pengujian, analisis data, dan pembuatan. Untuk tabel komposisi variasi $D O P$ dalam resin $P V C$, blowing agent, dan pigmen hitam sebagaimana Tabel 1 .

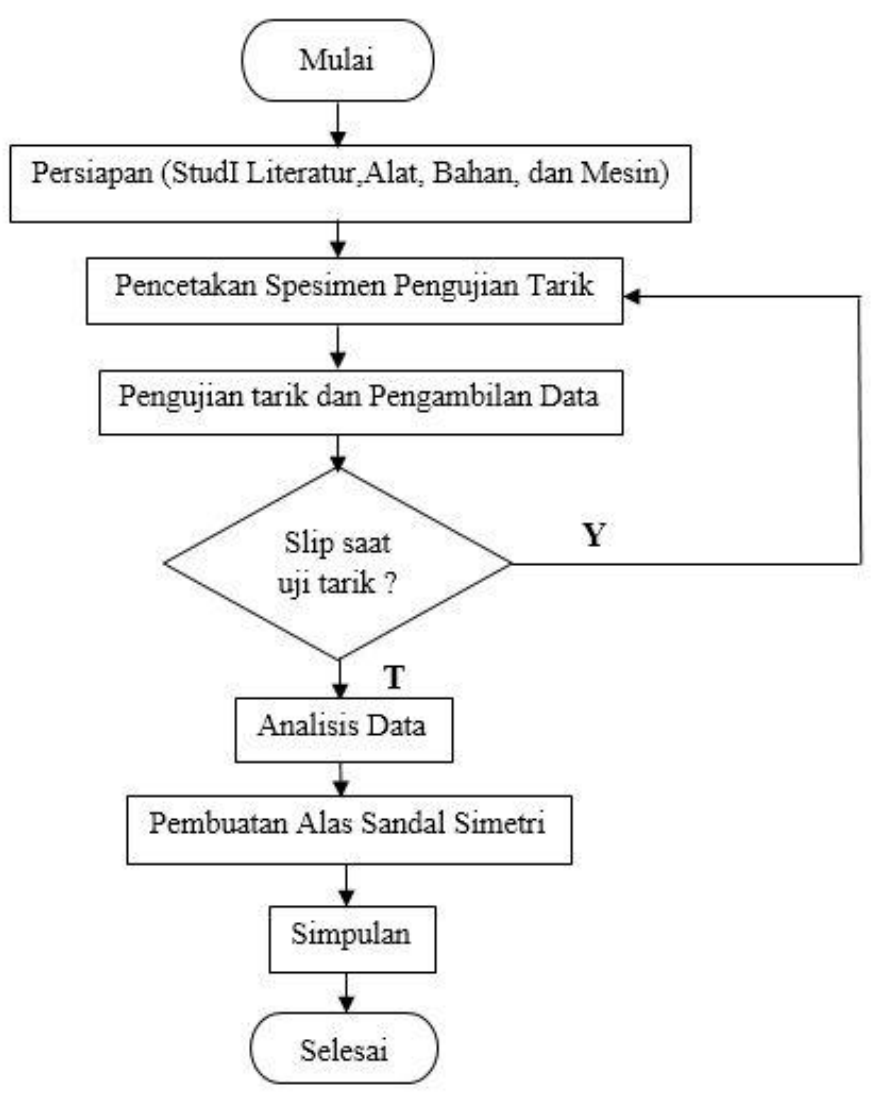

Gambar 4. Diagram alir penelitian

Tabel 1. Komposisi Variasi DOP dalam resin $P V C$, blowing agent, dan pigmen hitam

\begin{tabular}{|c|c|c|c|c|c|}
\hline \multirow[b]{2}{*}{$\mathrm{NO}$} & \multirow[b]{2}{*}{$\begin{array}{c}\text { Kode } \\
\text { Bahan }\end{array}$} & \multirow[b]{2}{*}{$\begin{array}{c}D O P \\
(\mathrm{ml})\end{array}$} & \multirow[b]{2}{*}{$\begin{array}{c}\text { Resin } \\
P V C \\
(g)\end{array}$} & \multicolumn{2}{|c|}{ Bahan Tambah } \\
\hline & & & & $\begin{array}{c}\text { Blowing } \\
\text { Agent } \\
(\mathrm{g})\end{array}$ & $\begin{array}{c}\text { Pigmen } \\
\text { Hitam } \\
(g)\end{array}$ \\
\hline 1. & $\mathrm{~A}$ & 300 & 2.000 & 20 & 20 \\
\hline 2. & B & 400 & 2.000 & 20 & 20 \\
\hline 3. & C & 500 & 2.000 & 20 & 20 \\
\hline
\end{tabular}

Pada proses pencetakan spesimen uji tarik standar ASTM D638-14 menggunakan cetakan spesimen sebagaimana Gambar 5.

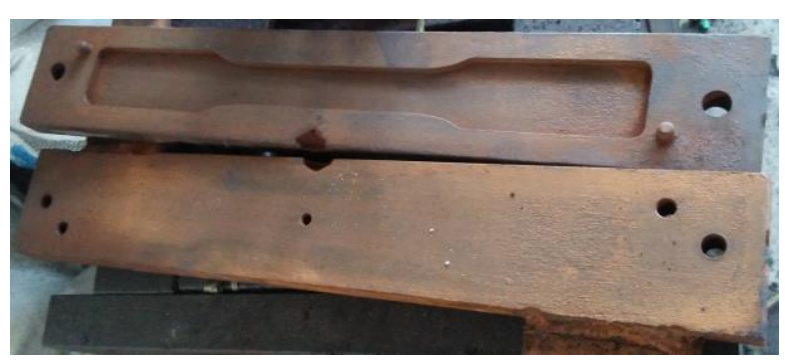

Gambar 5. Cetakan Spesimen ASTM D638-14

\section{Hasil dan Pembahasan}

Hasil pengujian tarik menggunakan mesin uji tarik sebagaimana Gambar 6.

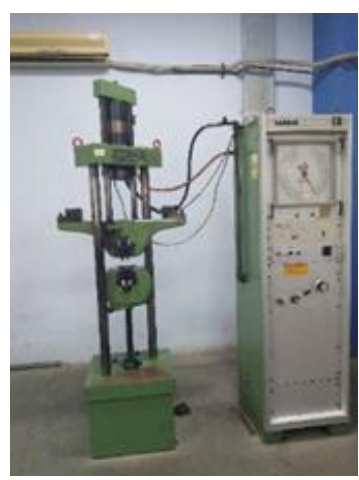

Gambar 6. Mesin Uji Tarik Tarno Grocki

Hasil pencetakan spesimen uji tarik standar ASTM D638-14 sebagaimana Gambar 7. Dimensi ukuran spesimen uji tarik standar ASTM D638-14 sebagaimana Gambar 8 [7].

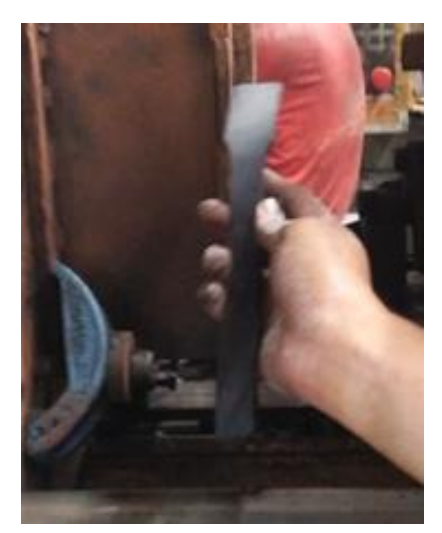

Gambar 7. Hasil pencetakan spesimen uji tarik 


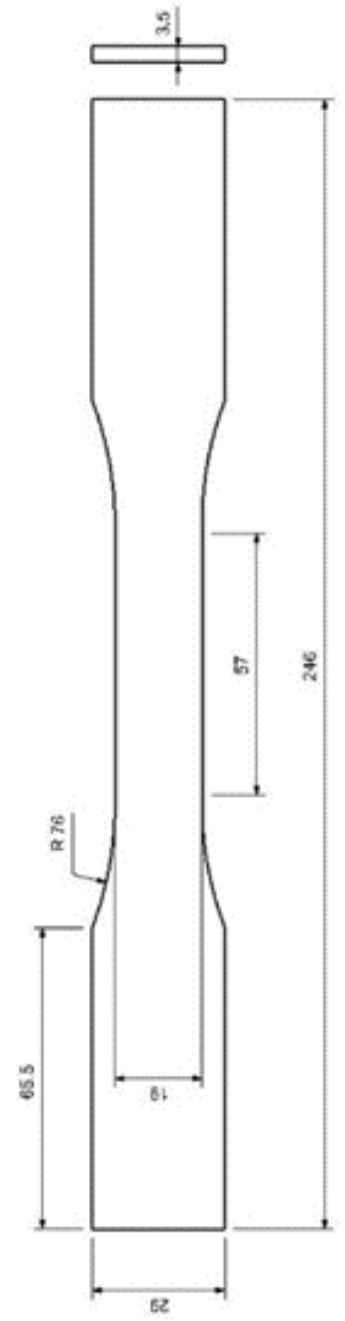

Gambar 8. Spesimen ASTM D638-14

Hasil pencetakan spesimen uji tarik kemudian di uji tarik pada mesin tarno grocki. Spesimen uji tarik yang telah diuji tarik sebagaimana Gambar 9.

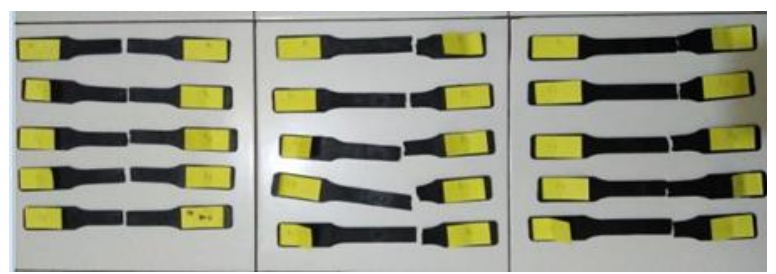

Gambar 9. Spesimen yang telah diuji tarik

Data yang diperoleh dalam pengujian tarik sebagaimana Tabel 2.
Tabel 2. Data pengujian tarik variasi $D O P$ dalam resin $P V C$

\begin{tabular}{|c|c|c|c|c|c|c|c|c|c|}
\hline \multirow{2}{*}{ NO. } & \multicolumn{3}{|c|}{ Gaya Tarik (kg) } & \multicolumn{3}{|c|}{ Kekuatan Tarik (MPa) } & \multicolumn{3}{|c|}{$\begin{array}{c}\text { Tegangan Luluh } \\
\text { (MPa) }\end{array}$} \\
\hline & FA & FB & FC & $\sigma_{\mathrm{t}} \mathrm{A}$ & $\sigma_{t} \mathrm{~B}$ & $\sigma_{\mathrm{t}} \mathrm{C}$ & $\sigma_{\mathrm{ytA}}$ & $\sigma_{\mathrm{ytB}}$ & $\sigma_{\mathrm{ytC}}$ \\
\hline 1. & 82,7 & 69,5 & 62,2 & 12,44 & 10,45 & 9,35 & 4,21 & 3,19 & 2,58 \\
\hline 2. & 86,55 & 66,7 & 59,35 & 13,02 & 10,03 & 8,92 & 5,77 & 2,58 & 2,73 \\
\hline 3. & 107,7 & 67,8 & 58,15 & 16,20 & 10,20 & 8,74 & 12,09 & 6,14 & 4,35 \\
\hline 4. & 93,9 & 67,55 & 63,30 & 14,12 & 10,16 & 9,52 & 9,94 & 5,82 & 5,3 \\
\hline 5. & 89,3 & 66,55 & $59 ., 0$ & 13,43 & 10,01 & 8,90 & 3,04 & 6,09 & 4,16 \\
\hline \multicolumn{10}{|c|}{$\begin{array}{l}\text { Keterangan: } \\
\text { FA= Gaya tarik spesimen A komposisi DOP } 300 \mathrm{ml} \text { dalam } 2000 \text { gram Resin PVC. } \\
\text { FB= Gaya tarik spesimen B komposisi DOP 400ml dalam } 2000 \text { gram Resin PVC. } \\
\text { FC= Gaya tarik spesimen C komposisi DOP } 500 \mathrm{ml} \text { dalam } 2000 \text { gram Resin PVC. }\end{array}$} \\
\hline
\end{tabular}

Seteleh mendapatkan data kekuatan tarik, data selanjutnya diolah menjadi grafik dengan pengulangan atau replikasi sebanyak 5 kali sebagaimana Gambar 10.

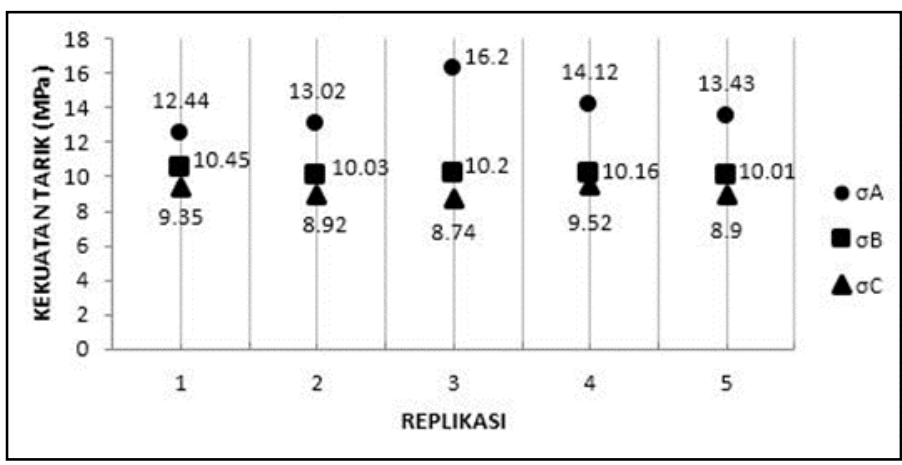

Gambar 10. Grafik kekuatan tarik variasi $D O P$ pada resin $P V C$

Berdasarkan Gambar 10 dapat dibahsa pengaruh variasi $D O P$ dalam resin $P V C$ sebagai berikut:

1. Kekuatan tarik pada takaran DOP $300 \mathrm{ml}$ dalam 2000g Resin PVC dengan simbol $\sigma_{t} \mathrm{~A}$ menghasilkan kekuatan tarik dengan nilai tertinggi yaitu 16,20 MPa dan yang paling rendah dengan nilai $12,44 \mathrm{MPa}$.

2. Kekuatan tarik pada takaran DOP $400 \mathrm{ml}$ dalam 2000g Resin PVC dengan simbol $\sigma_{t} B$ menghasilkan kekuatan tarik dengan nilai tertinggi yaitu $10,45 \mathrm{MPa}$ dan yang paling rendah dengan nilai 10,01 MPa.

3. Kekuatan tarik pada takaran DOP $500 \mathrm{ml}$ dalam $2000 \mathrm{~g}$ Resin PVC dengan simbol $\sigma_{t} \mathrm{C}$ menghasilkan kekuatan tarik dengan nilai tertinggi yaitu 9,52 MPa dan yang paling rendah dengan nilai 8,74 $\mathrm{MPa}$.

Setelah diuji tarik, salah satu bahan dicetak untuk dijadikan produk berupa alas sandal simetri. 
Pencetakan alas sandal simetri menggunakan cetakan alas sandal simetri sebagaimana Gambar 11 .

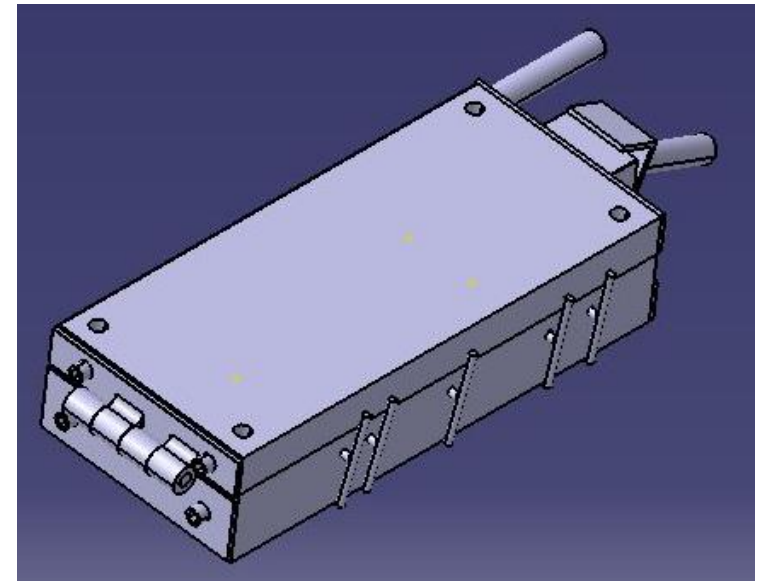

Gambar 11. Cetakan Alas Sandal Simetri

Alas sandal simetri yang dicetak menggunakan bahan dengan komposisi B dengan 400ml DOP dalam $2000 \mathrm{~g}$ resin $P V C, 20 \mathrm{~g}$ blowing agent, dan 20g pigmen hitam. Terdapat lubang dari atas menuju ke tepi sandal untuk meniriskan air pada alas sandal simetri tersebut. Hasil cetakan alas sandal simetri sebagaimana Gambar 12.

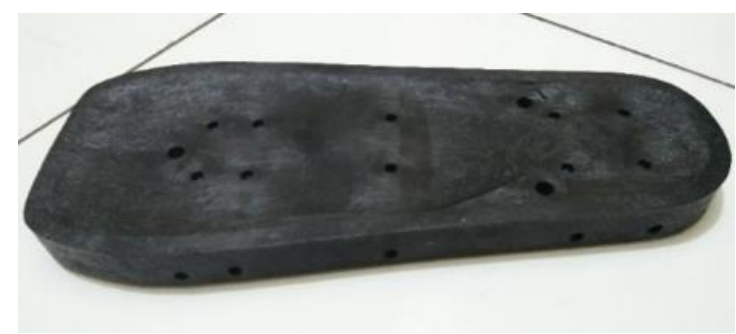

Gambar 12. Hasil pencetakan alas sandal simetri

\section{Kesimpulan}

Simpulan dalam penelitian pengaruh variasi komposisi DOP dalam resin $P V C$, blowing agent, dan pigmen hitam adalah semakin banyak komposisi $D O P$ dalam resin $P V C$ dari $300 \mathrm{ml} D O P$ ke $500 \mathrm{ml} D O P$ dalam 2000g resin PVC menurunkan kekuatan tarik resin $P V C$ sebesar $46 \%$ dari $16,20 \mathrm{MPa}$ ke $8,74 \mathrm{MPa}$.

Saran tindak lanjut atas kesimpulan, sebaiknya melakukan penelitian lebih lanjut untuk bahan alas sandal simetri, untuk mendapatkan bahan yang lebih lebih elastis, agar dapat menekan air keluar dari atas alas sandal menuju lubang samping sandal.

\section{Terima Kasih}

Terima kasih kepada Politeknik Negeri Malang atas bantuan dalam proses pengujian bahan dan UD Rumpun Mas Sidoarjo dalam pembuatan sandal simetri.

\section{Daftar Pustaka}

[1] Umam, Khairul, 2009, Pengaruh Penambahan Plastcizer Diocthyl Phtalate (DOP) Terhadap Mampu Alir dan Sifat Mekanik Resin Polyvinyl chloride (PVC), Skripsi, Universitas Indonesia, Jakarta.

[2] Michael, 2012, Studi Pengaruh Palsticizer Diethylene Glicol Dibenzoate (DEDB) Terhadap Modulus Elastisitas Dari Produk PVC, Skripsi, Universitas Indonesia, Jakarta.

[3] Sholeh, Muhammad, dan Rochani, Siti. 2018, Pengaruh pemlastis $D O P$ terhadap sifat fisis dan mekanis kulit sintetis, Skripsi, Universitas Indonesia, Jakarta.

[4] Surdia, Tata, dan Saito, Shinroku. 1999, Pengetahuan Bahan Teknik, Pradnya Paramitha, Jakarta. ISBN 9796880571.

[5] Gere, James M. dan Timoshenko, Stephen P. 1996, Mekanika bahan, Jakarta, Erlangga. ISBBN 9794082686 (buku terjemahan Mechanics of Material).

[6] Hadi, Syamsul, 2018, Teknologi Bahan Lanjut, Yogyakarta, Penerbit Andi. ISBN 9789792963663.

[7] Anonim, http://www.dept.aoe.vt.edu/ aborgolt/aoe3054/ manual/manual/expt5/D638.38935.pdf (diakses 11 Februari 2018). 